\title{
GROSS NATIONAL HAPPINESS, LIMITS TO GROWTH, AND \\ CHALLENGES FOR BHUTAN'S DEVELOPMENT APPROACH
}

Jeremy Brooks, PhD

Environmental and Social Sustainability Lab

School of Environment and Natural Resources

The Ohio State University 


\section{Starting points...}

$\square$ Impressions from

Bhutan

$\square 40$ year update of Meadows et al.'s

Limits to Growth

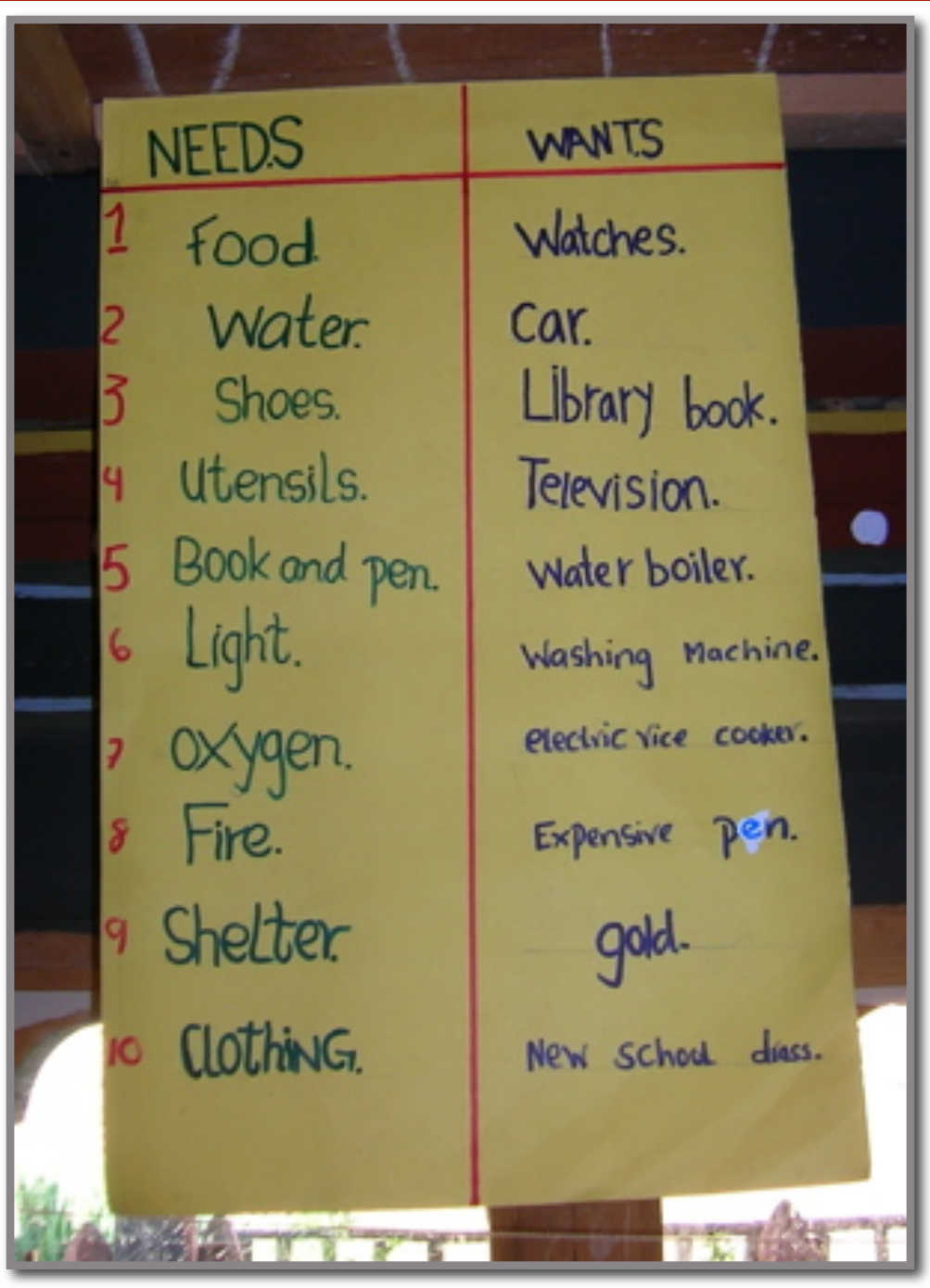




\section{0 year update to Limits to Growth}

1. How can we respond?

- Deny, disguise and confuse signals

- Markets, technology, and efficiency

- Change the system; structural, systemic change

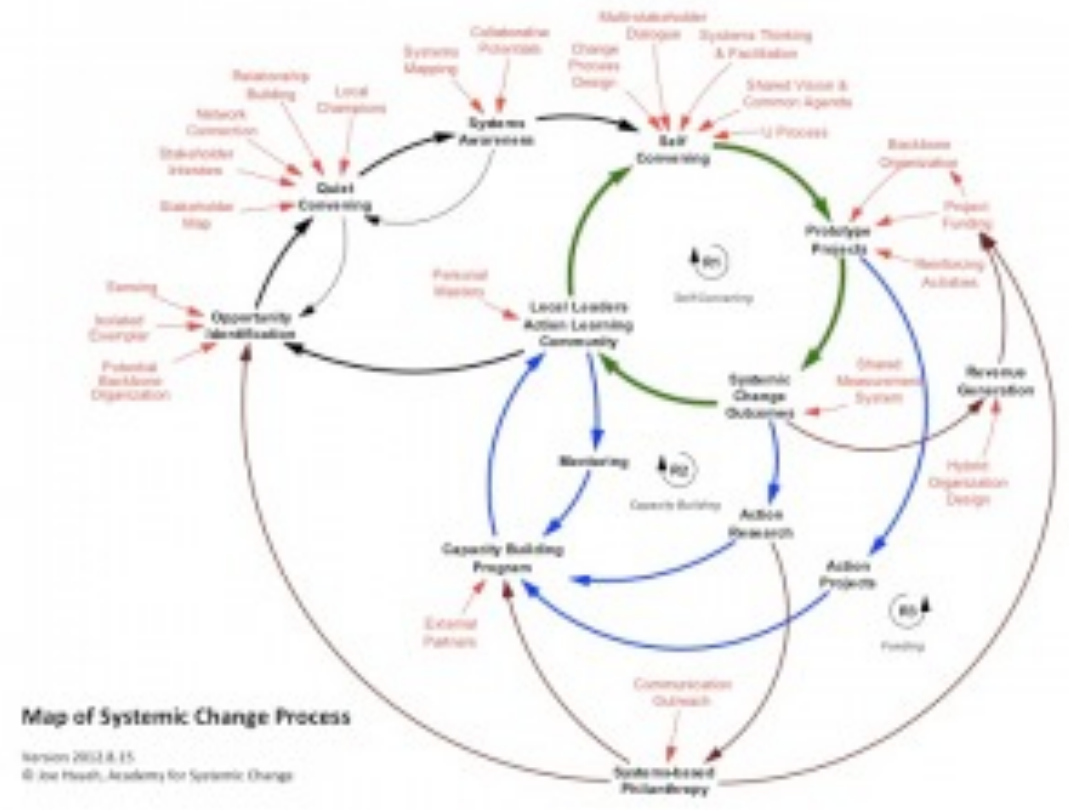




\section{0 year update to Limits to Growth}

2. How do you change the system?

i. need a vision of the kind of society we want

ii. Change the information and signals that guide decision-making

iii. Change social structures that impact desires, behaviors, and lifestyles 


\section{A new vision from Bhutan}

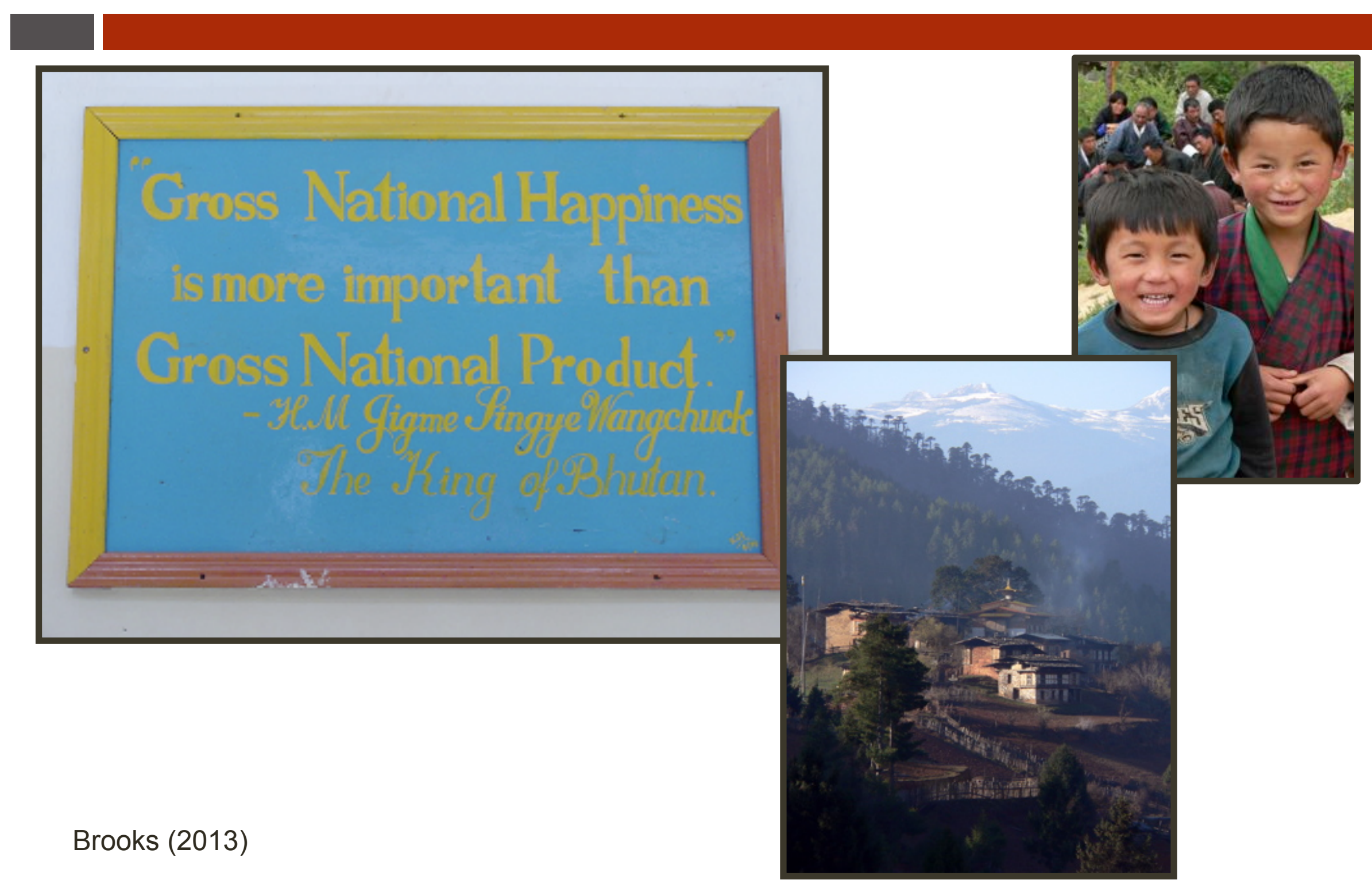




\section{A new vision from Bhutan}

Gross National Happiness as a development goal

"...maximize the happiness of all Bhutanese and to enable them to achieve their full and innate potential as human beings."(p. 12).

"...achieve a balance between the spiritual and material aspects of life...give preference to happiness and peace, even at the expense of economic growth, which we have regarded not as an end in itself, but as a means to achieve improvements in the well-being and welfare of the people."(p. 19). 


\section{Change the information/signals}

\section{Gross National Happiness Index}
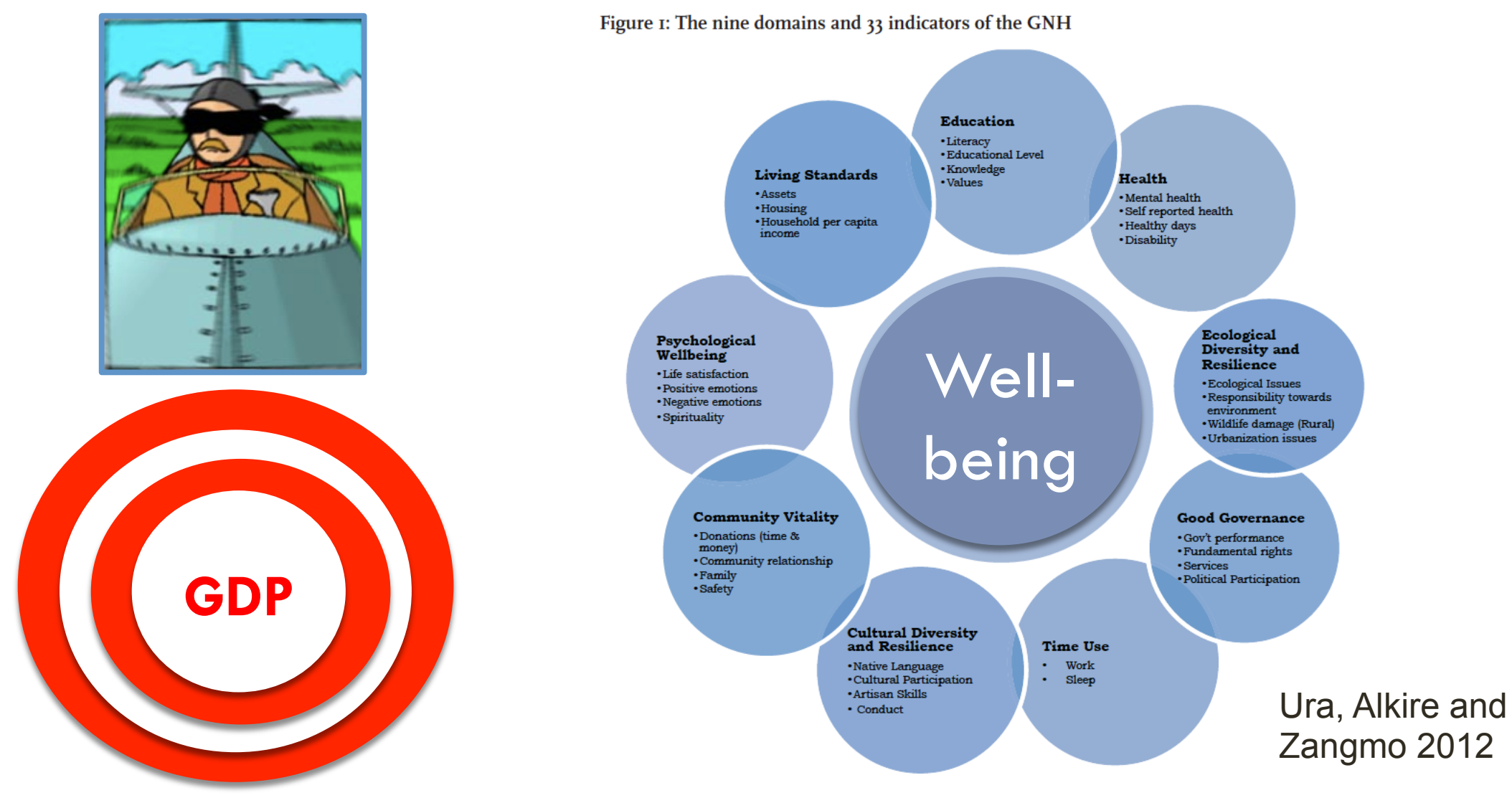


\section{Change social structures}

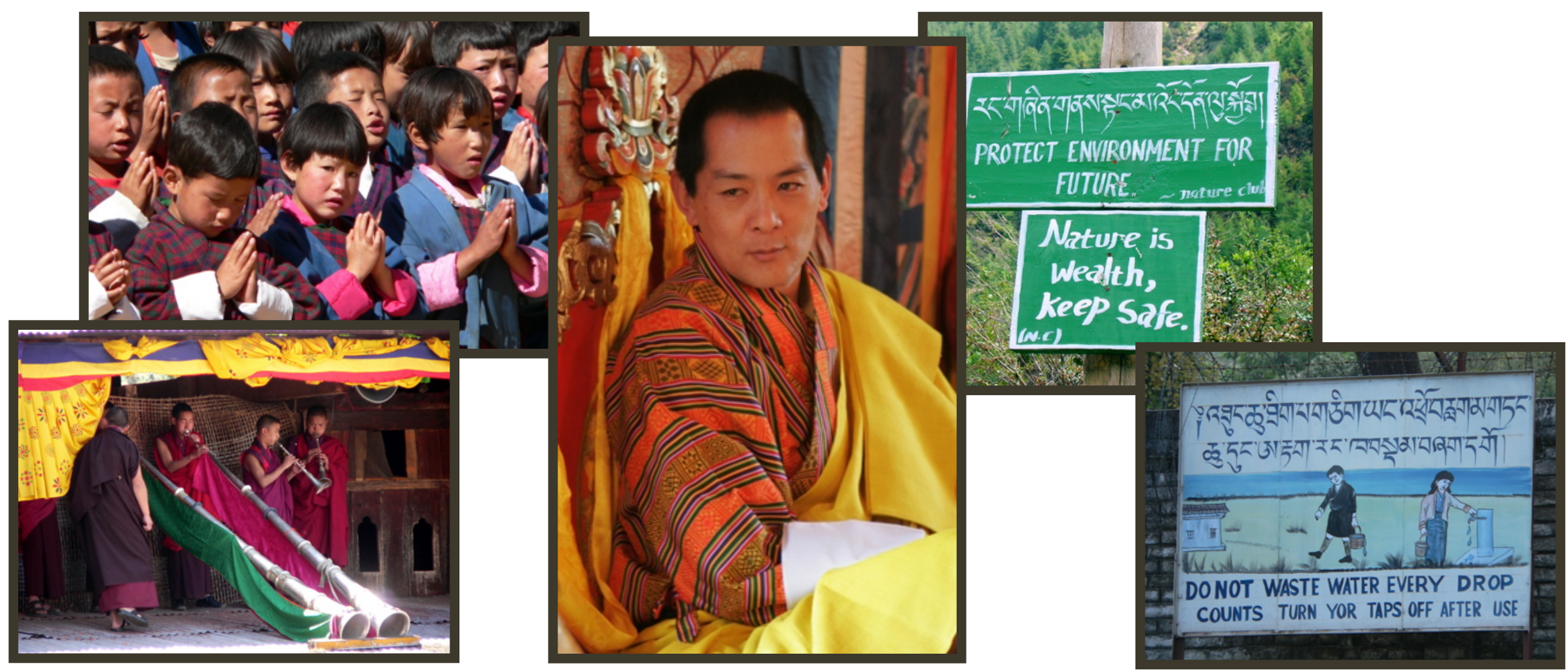

Creation of environmental citizens in Bhutan? 


\section{Change social structures}

Social norms for sustainability

Confluence of:

- Govt. goal of creating unique Buddhist identity

- Buddhist foundation of cultural traditions and national policies

- Govt. goal of linking Buddhism with conservation

- Unifying development principle of GNH 


\section{Challenges for Bhutan}

$\square$ Common identity = ethnic tension

$\square$ Competitive consumption/ impact of consumerism

$\square$ How to distinguish between consumption in service of well-being and over-consumption at multiple scales.

$\square$ Democracy: greater public voice=less interest in sustainable development and $\mathrm{GNH}$ ? 


\section{Conclusion}

$\square$ Bhutan has a new vision and a new metric

$\square$ Social norms are emerging and evolving

$\square$ Bhutan is experiencing the challenges of the process of developing a sustainable society

$\square$ More importantly, other countries are discussing new visions and adopting new metrics and measures

$\square$ The spread of their vision is already a critical contribution from the Bhutanese 